\title{
O PROJETO HERBÁRIO DIDÁTICO DO CAP-UERJ: SONDAGEM DAS CONCEPÇÕES DOS ALUNOS SOBRE REPRODUÇÃO E NUTRIÇÃO VEGETAL
}

\author{
Maria Cristina Ferreira dos Santos ${ }^{1}$ \\ CAP E FFP/UERJ \\ Lúcia Cristina da Cunha Aguiar ${ }^{2}$ \\ Anna Maria da Silva Matos ${ }^{3}$ \\ Marcelo Rodrigues Gamon ${ }^{4}$
}

CAP-UERJ

\section{RESUMO:}

Pesquisas feitas em todo o mundo já demonstraram que na área das ciências existem maneiras informais de fazer modelos e interpretar os fenômenos que são encontrados entre crianças de diferentes países, línguas e sistemas educacionais. O objetivo deste trabalho, desenvolvido dentro do "Projeto Herbário Didático do CAp-UERJ", foi fazer a sondagem das concepções dos alunos sobre reprodução e nutrição vegetal. O levantamento e a análise de tais ideias visam à pesquisa das dificuldades na compreensão dos conhecimentos científicos de forma a subsidiar estratégias alternativas de ensino. Muitas das concepções alternativas são recorrentes em diferentes séries escolares e pouco aceitas do ponto de vista científico. Para fazer a comparação entre diferentes séries foram utilizados dados levantados a partir de questionários sobre reprodução e nutrição vegetal aplicados em 2005 aos alunos do $5^{\circ}$. ano do Ensino Fundamental do CAp-UERJ e em 2007 o mesmo questionário foi reaplicado aos alunos do $7^{\circ}$. ano do Ensino Fundamental, que corresponde à cerca de $50 \%$ daqueles alunos que estavam no $5^{\circ}$. ano em 2005 . Algumas concepções de 2007 aproximam-se mais dos conceitos científicos e outras não mudaram significativamente em dois anos. Os resultados são importantes para a compreensão das dificuldades dos alunos no processo de ensino-aprendizagem em Ciências.

PalaVRas-Chave: herbário didático - ensino de ciências - ensino-aprendizagem

\section{ABSTRACT:}

Researches in science education have shown that children from diverse ethnic and cultural backgrounds often develop understandings about natural world which are quite different from those presented by scientific community. The aim of this work, which is part of the Didactic Herbarium Project that takes place in Cap-UERJ, was to identify scholars' understandings about reproduction and plant nutrition that they brought to the learning process. The recognition of some aspects of ideas' conceptual development can help provide insights into what strategies 
e-Mosaicos - Revista Multidisciplinar de Ensino, Pesquisa, Extensão e Cultura do Instituto de Aplicação Fernando Rodrigues da Silveira (CAp-UERJ) ANO 1 - V. 1 - N. 1 - JUNHO 2012 - ISSN: 2316-9303

will best deal with roadblocks to teaching and that will serve students' learning needs. During the process of developing the knowledge of how things work, many misconceptions - unscientific accepted ideas - can prevail and even persist over time. In 2005 students in 5th grade of the elementary school answered a questionnaire related to reproduction and plant nutrition. In 2007 the same questionnaire was applied again to the students in 7th grade $-50 \%$ of these students answered the questionnaire in 2005, when they were in 5th grade. The results provided interesting information about their conceptual development of ideas. Some inaccurate understandings appeared in both samples which suggested they remained the same after two years. The older scholars' responses showed a better understanding of the subjects. Exploring students' understandings of concepts provide information for, regarding misconceptions, finding the resources to support their learning and highlighting some consequences to science education.

KEYWORDS: didactic herbarium - science education - learning process

\section{INTRODUÇÃO}

Quando as crianças entram na escola e por toda a sua vida escolar elas já tem ideias pré-formadas sobre como funciona 0 mundo natural. Pesquisas feitas em todo o mundo já demonstraram que, na área das ciências, existem maneiras informais de fazer modelos e interpretar os fenômenos que são encontrados entre crianças de diferentes países, línguas e sistemas educacionais. Como exemplos dessas concepções alternativas relacionadas às plantas identificadas com maior frequência, podemos citar:

- As plantas retiram o alimento do ambiente ao invés de produzi-lo internamente;

- Água e minerais são alimentos para as plantas;

- O solo é o alimento da planta. Os fertilizantes são colocados no solo para as plantas se alimentarem;

- As plantas retiram o alimento pelas raízes e então o armazenam em suas folhas;

Hershey $(2004,2005)$ reconhece seis categorias de concepções errôneas relacionadas ao ensino de botânica: simplificações ou generalizações exageradas, generalizações simplificadas, uso de termos e conceitos obsoletos, identificações errôneas e pesquisas com resultados não-comprovados, e argumenta que os professores frequentemente não detectam estes erros por falta de uma boa formação em botânica básica durante o curso universitário. Abaixo estão alguns exemplos:

Reprodução assexuada e reprodução vegetativa não são sinônimas: a reprodução vegetativa está relacionada à formação de uma nova planta a partir de órgãos vegetais, como caules, folhas e raízes, enquanto que a apomixia seria uma forma de produção de sementes por reprodução assexuada;

Os taxonomistas vegetais usavam a palavra Divisão para referir-se aos grupos correspondentes aos Filos na Zoologia, mas atualmente pode ser usado o termo Filo tanto na Botânica como na Zoologia. 
e-Mosaicos - Revista Multidisciplinar de Ensino, Pesquisa, Extensão e Cultura do Instituto de Aplicação Fernando Rodrigues da Silveira (CAp-UERJ) ANO 1 - V. 1 - N. 1 - JUNHO 2012 - ISSN: 2316-9303

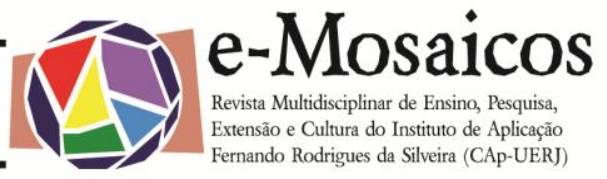

\section{O Projeto Herbário Didático do CAP/UERJ}

Um herbário didático consiste em uma coleção de plantas secas e herborizadas segundo determinadas técnicas, mantida em instalações apropriadas e em condições adequadas de conservação, servindo como documentação da flora de uma região. 0 herbário é utilizado na identificação de plantas para vários fins, entre eles o paisagismo, levantamento da flora, fitoquímica, avaliação do desmatamento e treinamento e capacitação de pessoal especializado em taxonomia vegetal (SINGH, 1999). Coleções de frutos (carpoteca), lâminas (laminário) e madeiras (xiloteca) podem ser estar associadas e todos estes materiais podem ser utilizados como recursos didáticos nas aulas das disciplinas escolares Ciências e Biologia no ensino fundamental e médio.

\section{OBJETIVOS}

Este trabalho foi desenvolvido dentro do Projeto Herbário Didático do CAp-UERJ e os objetivos foram: 1) a montagem e a organização de material botânico para o Herbário Didático e coleções associadas no Instituto de Aplicação Fernando Rodrigues da Silveira (CAp-UERJ), e 2) o estudo das principais dificuldades no processo ensinoaprendizagem nas disciplinas Ciências e Biologia. A proposta é incentivar os professores, alunos do CAp-UERJ e licenciandos a buscar formas alternativas de ensino de ciências através de aulas práticas, confecção de coleções e outros recursos didáticos.

\section{Metodologia}

\section{Organização do herbário e material didático}

A montagem de um herbário começa com a coleta em campo dos espécimes que depois passam por um processo denominado de herborização, que consiste na prensagem, secagem e preparação do exemplar botânico para inclusão na coleção. A coleta das plantas vasculares é realizada com tesouras de poda para ervas, subarbustos e arbustos e através de podão para árvores. Os espécimes recebem uma numeração e uma ficha onde são registrados os dados anotados durante a coleta (IBGE, 1992). Depois de coletado o material é prensado, utilizando-se para isso prensas de madeira, papel borrão ou chupão, folhas de alumínio corrugado e jornais. Posteriormente a prensa é levada para a estufa, que desidratará o material botânico (IBGE, 1992). Os frutos e sementes, quando de grande tamanho, devem ser colocados na estufa em sacos de papel, separadamente das plantas prensadas. As Briófitas devem ser secas à temperatura ambiente, em sacos de papel ou levemente prensadas entre jornal ou papelchupão, mas nunca colocadas em prensa (FIDALGO \& BONONI, 1984). O exemplar seco é fixado através de costura ou cola a uma cartolina (camisa) que será envolta por uma folha de papel Kraft (saia), que protegerá a planta. Existem dimensões padronizadas para a camisa $(42 \times 29 \mathrm{~cm})$ e para a saia $(42 \times 60 \mathrm{~cm})$. Ao conjunto camisa, planta e saia denomina-se "exsicata". Os frutos e sementes secos que sejam grandes para as exsicatas devem ser guardados na carpoteca do herbário, com o mesmo número de registro usado para o resto do espécime. As exsicatas de preferência são confeccionadas com os espécimes vegetais coletados em regiões do entorno da escola ou de suas moradias, e incorporadas ao Herbário Didático da Escola.

Famílias, gêneros e espécies foram dis- 
e-Mosaicos - Revista Multidisciplinar de Ensino, Pesquisa, Extensão e Cultura do Instituto de Aplicação Fernando Rodrigues da Silveira (CAp-UERJ) ANO 1 - V. 1 - N. 1 - JUNHO 2012 - ISSN: 2316-9303

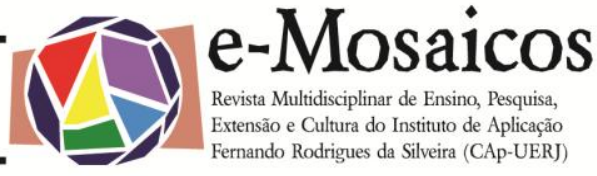

tribuídos nas cartolinas por ordem alfabética. As exsicatas são conservadas em armários em locais secos. É conveniente guardálas dentro de sacos plásticos com cânfora e naftalina e depois então colocá-las nos armários ou latas. Este procedimento evita o ataque de insetos. Periodicamente pode ser feita a aplicação de inseticidas nas plantas para eliminar ou repelir os insetos (MORI et al, 1985). Para a determinação das espécies é consultada a bibliografia específica e realizada a comparação do material herborizado com o depositado em outros herbários.

\section{Levantamento das concepções dos a- lunos}

Em 2005 questionários com perguntas sobre reprodução vegetal foram respondidos por 55 alunos das três turmas de $4^{a}$ série (atual $5^{\circ}$ ano) do CAp-UERJ. Logo após a aplicação dos questionários foi ministrada uma aula teórica seguida de demonstração prática sobre os órgãos reprodutores das plantas. Os materiais foram visualizados no microscópio estereoscópico de forma a evidenciar estruturas como ovário, óvulos e pólen na flor; e epicarpo, mesocarpo, endocarpo e sementes no fruto, entre outras, e comparar com a reprodução no homem, de acordo com o planejamento proposto pela professora de classe. Cerca de quarenta dias após a aula o questionário foi reaplicado nas três turmas (SANTOS et al, 2005). Em 2007 este mesmo questionário foi reaplicado a 99 alunos de turmas do $7^{\circ}$ ano (antiga $6^{\mathrm{a}}$ série), correspondendo cerca de $50 \%$ dos alunos aqueles que cursavam a $4^{\mathrm{a}}$ série (atual $5^{\circ}$ ano) e desenvolveram as atividades em 2005 no CAp e o restante a alunos oriundos de concurso para $\circ 6^{\circ}$ ano.

\section{RESUltados e Discussão}

\section{O Herbário Didático do CAp/UERJ}

A montagem e organização de um herbário didático permitem vivenciar tanto 0 trabalho de campo como os procedimentos em laboratório para o preparo do material. Também as coleções de madeiras, sementes e frutos secos constituem-se em material a ser usado nas salas de aula e práticas laboratoriais. O Herbário Didático do Instituto de Aplicação Fernando Rodrigues da Silveira da Universidade do Estado do Rio de Janeiro (CAp-UERJ) está situado na Rua Santa Alexandrina, 288 - Rio Comprido, Rio de Janeiro, no quarto andar do Bloco B, nos Laboratórios de Ciências e Biologia, principalmente representado por plantas ornamentais, medicinais e frutíferas dos arredores. Este material é utilizado nas aulas do Ensino Fundamental e Médio deste Instituto.

\section{As ideias dos alunos do CAp/UERJ so- bre reprodução e nutrição vegetal}

Alguns resultados das pesquisas em desenvolvimento no Instituto de Aplicação Fernando Rodrigues da Silveira (CAp) da UERJ em que foram enfatizadas as diferenças entre as ideias informais e a visão científica sobre reprodução e nutrição vegetal dos alunos que cursavam a antiga $4^{\mathrm{a}}$ série (atual $5^{\circ}$ ano) em 2005 e dos alunos que estão cursando o $7^{\circ}$ ano em 2007 foram apresentados a seguir. Não foram observadas diferenças significativas nas respostas dos alunos que cursaram todo o ensino fundamental no CAp e aqueles que entraram no concurso para o $6^{\circ}$ ano.

Observou-se que o percentual de citações relacionado à organografia vegetal $(34,6 \%)$ continuou elevado e que a ideia de que ter clorofila é característica marcante 
e-Mosaicos - Revista Multidisciplinar de Ensino, Pesquisa, Extensão e Cultura do Instituto de Aplicação Fernando Rodrigues da Silveira (CAp-UERJ)

ANO 1 - V. 1 - N. 1 - JUNHO 2012 - ISSN: 2316-9303

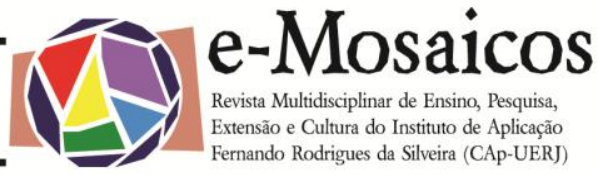

das plantas ( $16,2 \%$ no 70 ano), sendo este percentual maior do que o observado na $4^{a}$ série (Figuras 1 e 2). Em trabalho realizado por Santos e colaboradores (2006) também foram enfatizadas a organografia vegetal e a presença de clorofila nas respostas dos alunos.

Características relacionadas à reprodução da planta, como pólen, órgãos reprodutores e óvulo só apareceram em $10 \%$ das citações no $7^{\circ}$ ano (Figura 2), contrapondose a mais de $30 \%$ das citações pós-aula na $4^{\mathrm{a}}$ serie (Figura 1). A grande diferença no $7^{\circ}$ ano é o aparecimento de citações ao nível microscópico: células e organização celular $(9,5 \%)$ e átomos/moléculas e substâncias $(16,2 \%)$ (Figura 2). Estas ideias não são tão frequentemente encontradas como esperado: Banet e Ayuso (1995) relataram que estudantes de ensino médio indicavam a existência de células apenas no homem, entendendo que pequenos invertebrados e plantas não apresentariam estrutura celular.

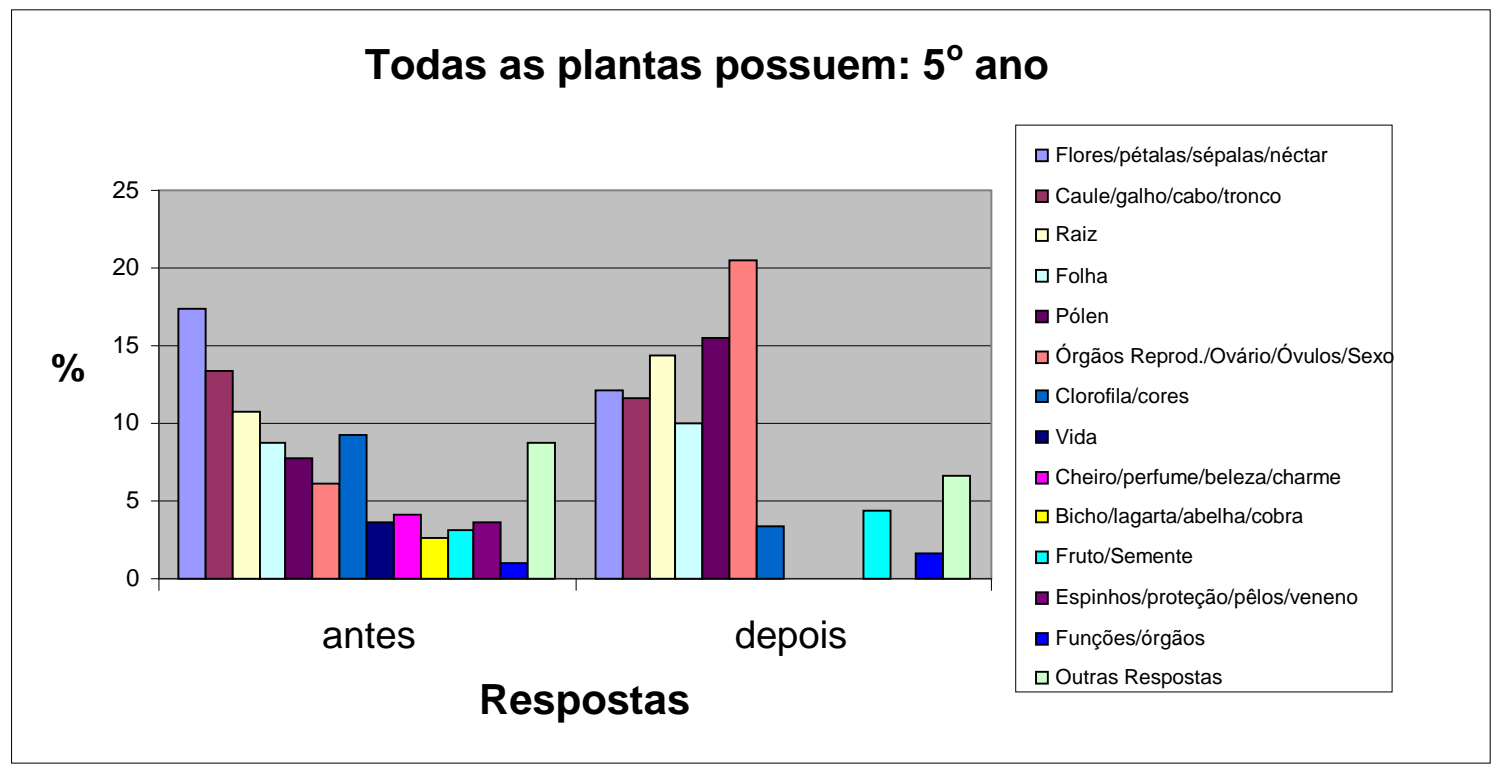

Figura 1. Respostas (\%) dos alunos do $5^{\circ}$ ano ( $4^{\mathrm{a}}$ série) antes e depois da aula sobre reprodução das plantas à questão "Todas as plantas possuem..." (SANTOS et al, 2005).

A noção de autotrofia como característica de plantas, inexistente nas respostas da $4^{\mathrm{a}}$ série em 2005, aparece em $6 \%$ das citações e pode estar indicando o resultado das atividades desenvolvidas no $6^{\circ}$ ano em 2006 e também na ênfase dada à forma de nutrição como critério importante de classificação dos seres vivos desenvolvida no 70 ano em 2007. 5,4\% das citações faziam refe- rência às seivas vegetais, o que cor-robora a fixação de alguns pontos das atividades realizadas durante o $6^{\circ}$ ano em 2006.

Entre as concepções alternativas destacamos: "uma célula, várias raízes, sementes, fazem reprodução pela fotossíntese" e "clorofila, nutrição autotrófica, respiração anaeróbica, reprodução assexuada, células eucariontes". 
e-Mosaicos - Revista Multidisciplinar de Ensino, Pesquisa, Extensão e Cultura do Instituto de Aplicação Fernando Rodrigues da Silveira (CAp-UERJ) ANO 1 - V. 1 - N. 1 - JUNHO 2012 - ISSN: 2316-9303

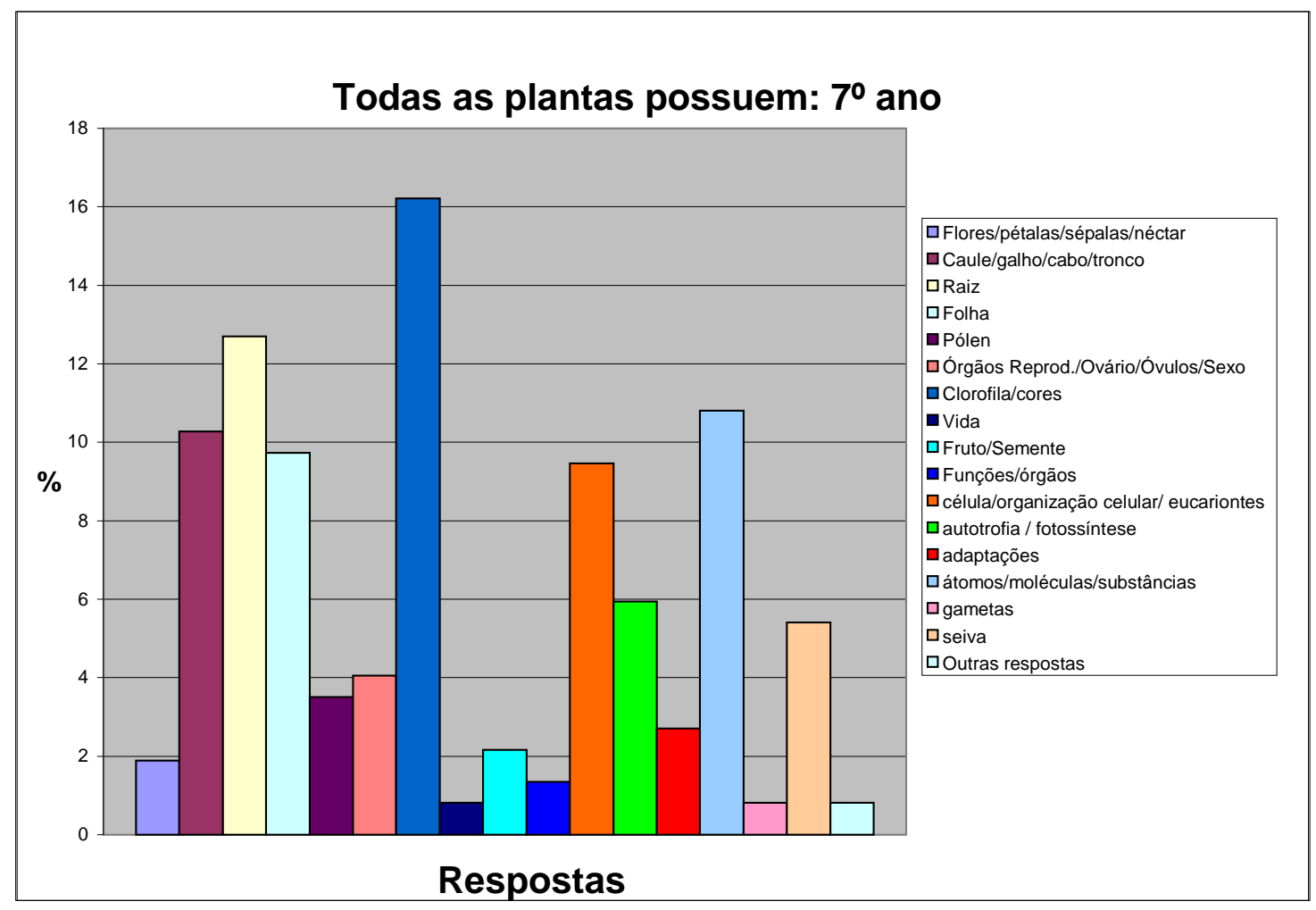

Figura 2. Respostas (\%) dos alunos do 70 ano à questão "Todas as plantas possuem...".

Na 4a série há ênfase na ação de outros seres na reprodução vegetal (animais carregam sementes). Já no 70 ano só $14,2 \%$ das citações deram ênfase aos animais participando da reprodução e há grande percentual de citações em torno da participação do pólen e transferência de óvulo/gametas (Figura 4). Estas respostas não apareceram nos questionários antes da aula na $4^{a}$ série e foram observadas em $10 \%$ das respostas após a aula (Figura 3).

Quando perguntados sobre a diferença entre a reprodução das plantas e dos animais os alunos do 70 ano associaram a reprodução sexuada ao ato de acasalar: $30,7 \%$ dos alunos do $7^{\circ}$ ano responderam que as plantas têm reprodução assexuada e apenas $1 \%$ respondeu reprodução sexuada, enquanto que para os animais $43,2 \%$ das respostas indicaram a reprodução sexuada (Figura 6). Esta polarização nítida no $7^{\circ}$ ano foi semelhante à modificação verificada nas respostas pós-aula da $4^{a}$ série, em que mais de $40 \%$ das citações indicavam que os animais precisam de um parceiro e as plantas não (Figura 5).

Também responderam que as plantas precisam de um terceiro organismo, da água ou do vento para se reproduzir $(8,5 \%)$. Este percentual foi inferior ao observado nas respostas na $4^{\mathrm{a}}$ série. Apenas $0,5 \%$ respondeu que as plantas podem apresentar fecundação interna (Figura 6). 


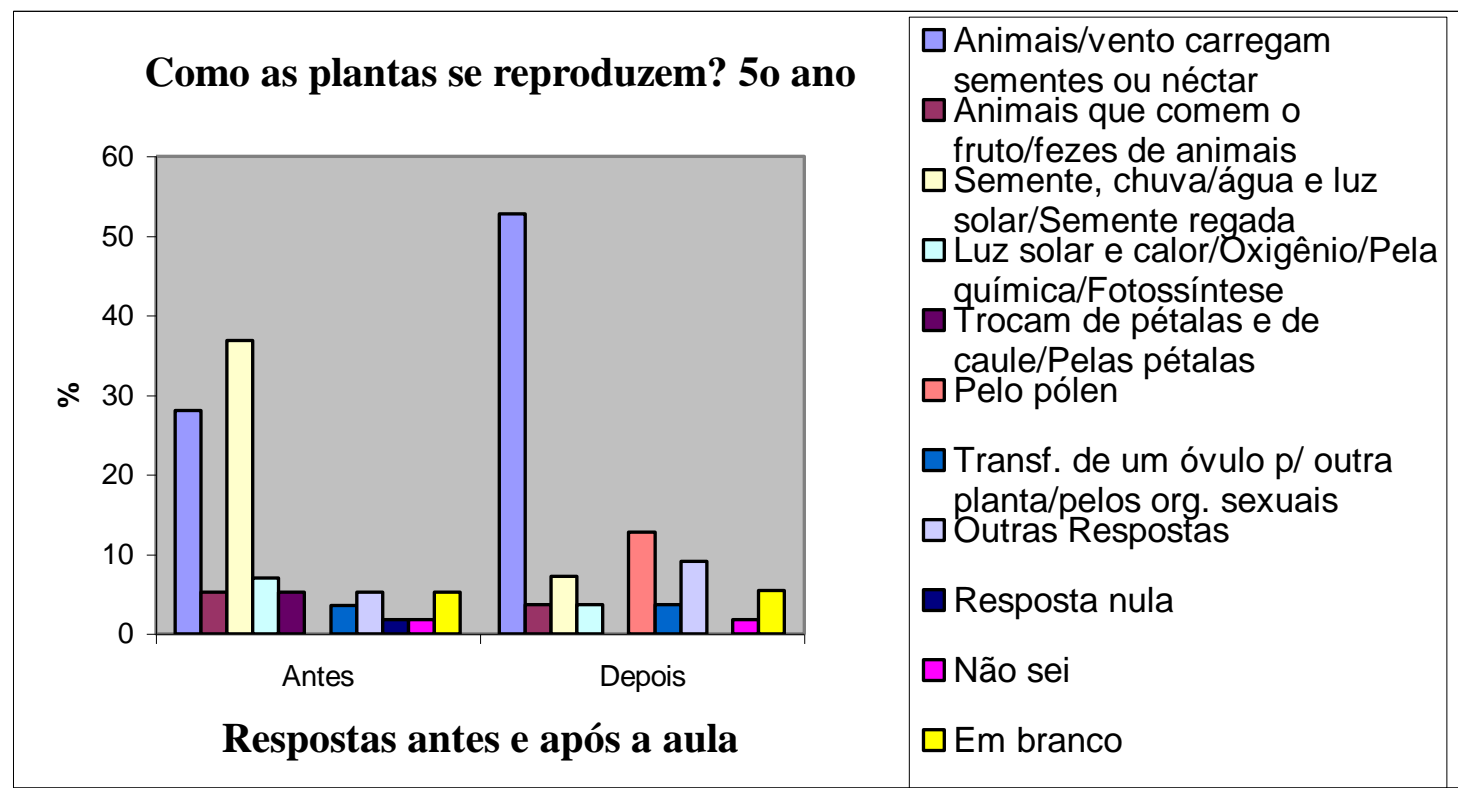

Figura 3. Respostas (\%) dos alunos do $5^{\circ}$ ano (4a série) antes e depois da aula sobre reprodução das plantas à questão "Como as plantas se reproduzem?" (SANTOS et al, 2005).

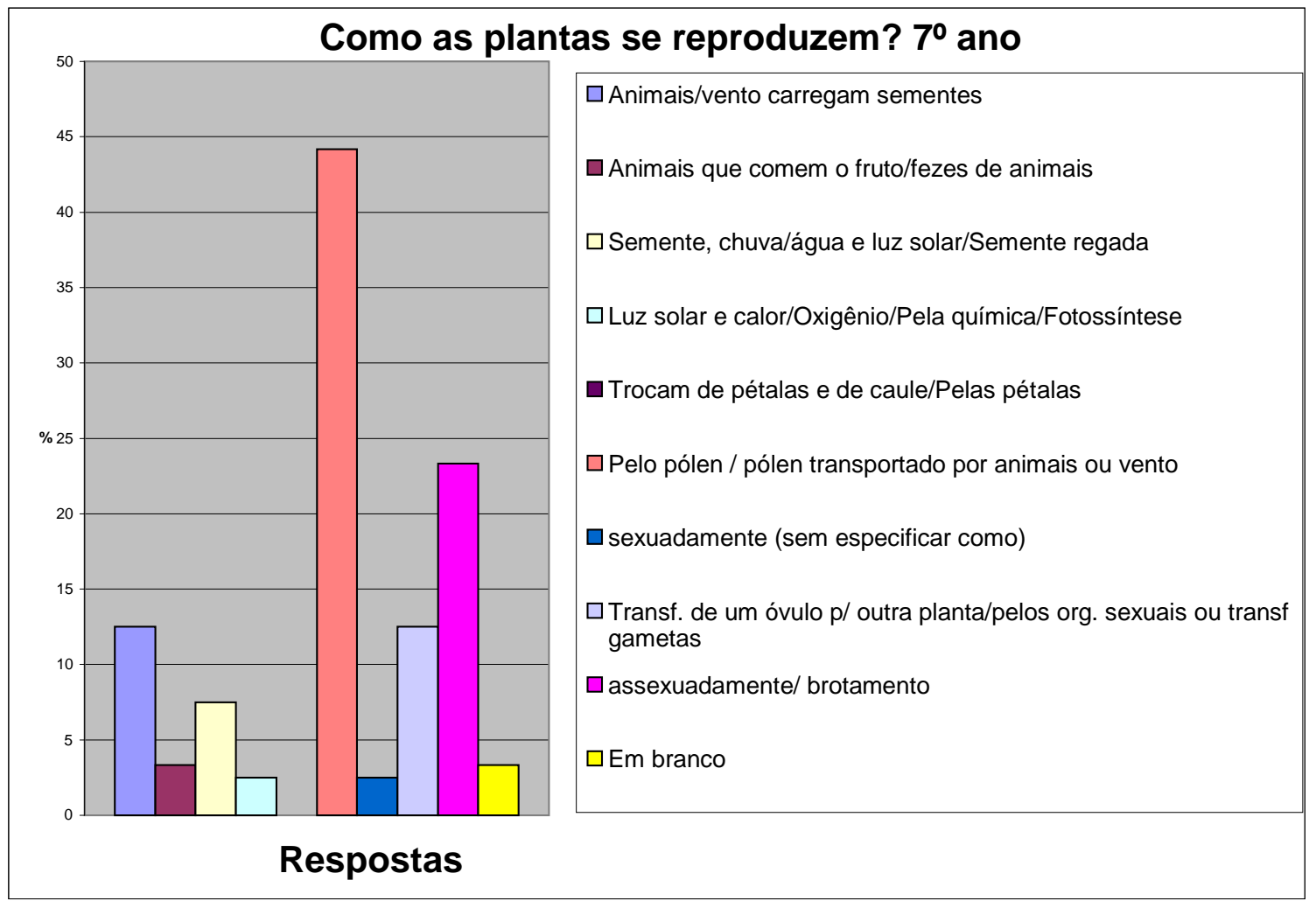

Figura 4. Respostas (\%) dos alunos do 70 ano à questão "Como as plantas se reproduzem?". 


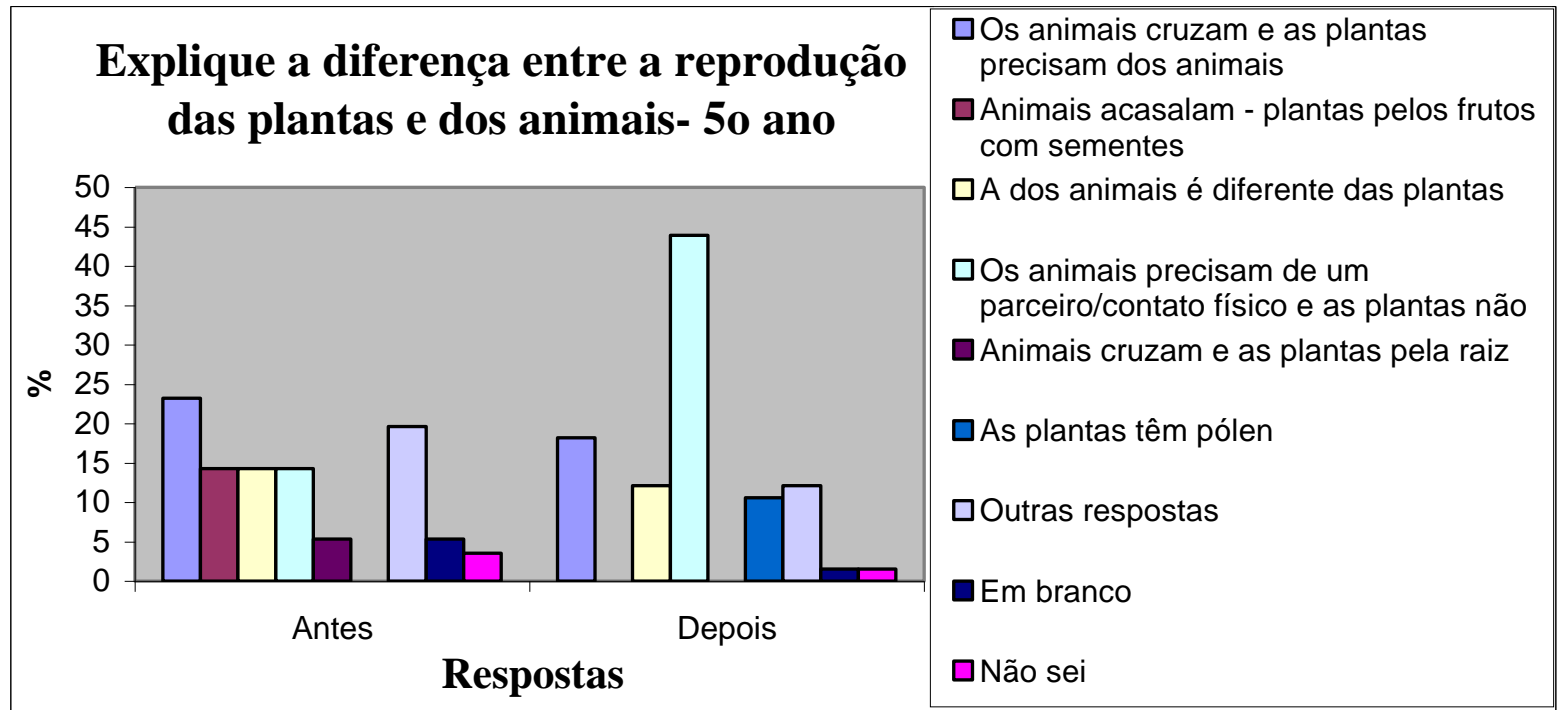

Figura 5. Respostas (\%) dos alunos do $5^{\circ}$ ano antes e depois da aula sobre reprodução das plantas à questão "Explique a diferença entre a reprodução das plantas e dos animais" (SANTOS et al, 2005).

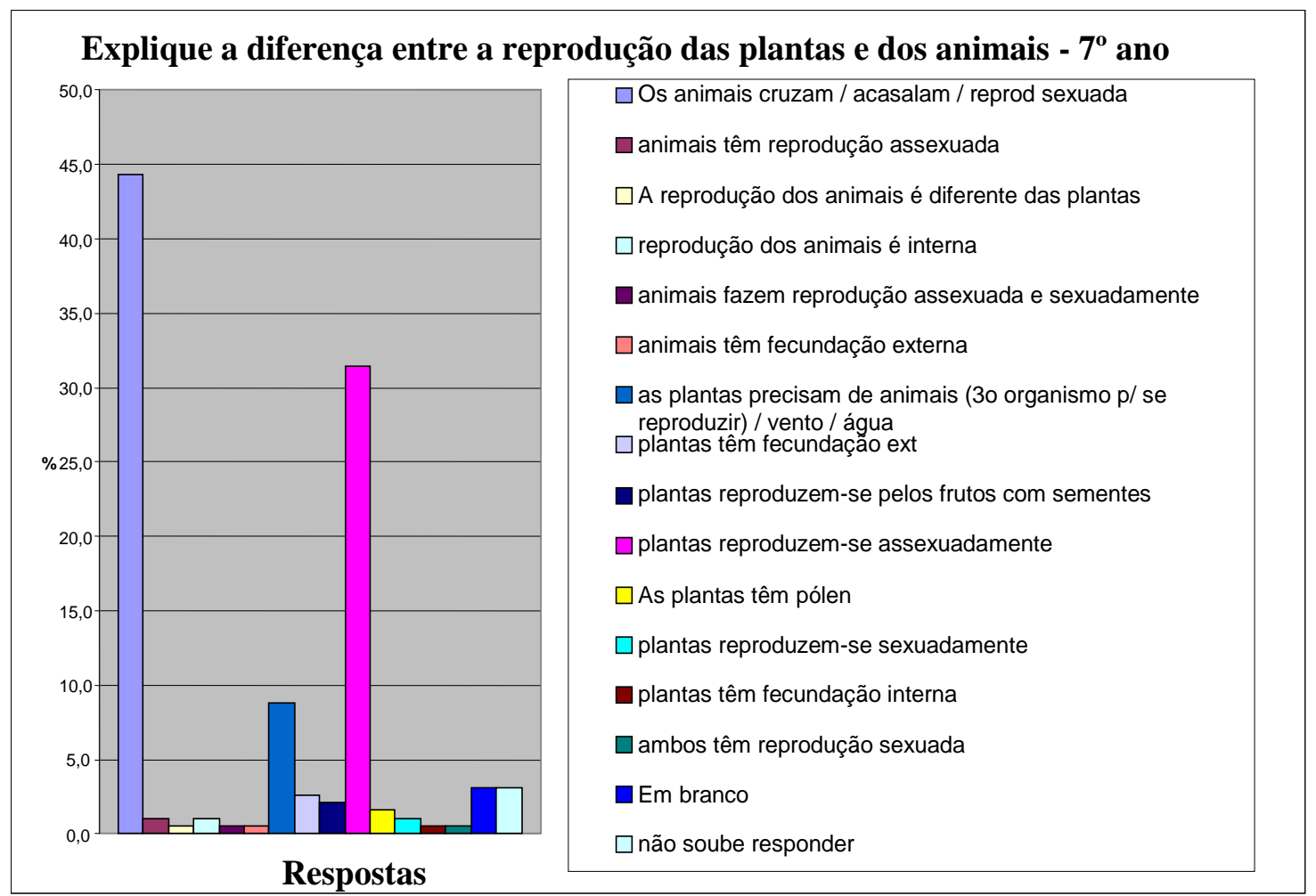

Figura 6. Respostas (\%) dos alunos do 70 ano à questão "Explique a diferença entre a reprodução das plantas e dos animais". 
e-Mosaicos - Revista Multidisciplinar de Ensino, Pesquisa, Extensão e Cultura do Instituto de Aplicação Fernando Rodrigues da Silveira (CAp-UERJ) ANO 1 - V. 1 - N. 1 - JUNHO 2012 - ISSN: 2316-9303

Entre o $5^{\circ}$ e $7^{\circ}$ anos ocorreram mudanças significativas na percepção dos alunos acerca da nutrição vegetal (Figuras 7 e 8). Enquanto que na $4^{a}$ série ( $5^{\circ}$ ano) mesmo após as informações da aula sobre este assunto, $41,7 \%$ dos alunos consideravam que a planta obtinha seu alimento pela raiz. Estudos vêm demonstrando que, de um modo geral, os conceitos sobre nutrição vegetal são entendidos de forma confusa e fragmentada (SENICIATO \& CAVASSAN, 2004). Neste aspecto, a produção de alimentos pelo vegetal a partir de compostos inorgânicos apareceu em quase a metade das respostas $(47,4 \%)$ no $7^{\circ}$ ano, através da identificação de fenômenos como a absorção de alimento subterrâneo, pela terra, pelo adubo, água ou chuva e pela raiz onde ocorreu associação à nutrição vegetal a processos biológicos incompletos ou tendo a intervenção humana para permitir a sobrevivência da planta. Neste contexto, algumas respostas citadas foram: "Pela foIha", "A planta obtém seu alimento pelo solo", "Pela sua rais" (sic) e "Pelo ar e pela água". O uso de conceitos cientificamente corretos muitas vezes é substituído por concepções espontâneas formuladas pelos alunos (SENICIATO \& CAVASSAN, 2004), conforme verificado em $47 \%$ das respostas dadas. Este percentual, conforme verificado anteriormente, não foi muito diferente daquele obtido pelos alunos na $4^{\mathrm{a}}$ série (Figura 7).

Mais da metade $(52,6 \%)$ dos alunos do $7^{\circ}$ ano em 2007 identificaram o fenômeno de fotossíntese como sendo primordial para a planta sobreviver no ambiente, ou seja, como ela deveria obter seu alimento (Figura 8). Alguns exemplos de respostas neste ano foram: "Pela fotossíntese", "Através da fotossíntese", "Por meio da fotos-síntese" ou simplesmente "fotossíntese". Neste caso nenhum outro processo ou fenômeno biológico foi associado na resposta. Houve um aumento significativo no percentual destas respostas em relação à $4^{a}$ série em 2005 , onde apenas $8,3 \%$ (Figura 7) relacionaram a nutrição vegetal à fotossíntese.

Entre as concepções alternativas foram dadas as seguintes respostas: "Pela raiz, a planta suga os nutrientes do solo", "Pela raiz sugando a água e os minerais da terra", "Através da raiz a planta absorve água e nutrientes para sua alimentação", "Pela raiz que pega os nutrientes do solo", "Pela absorção de alimentos subterrâneos", "Pelo o (sic) caule e a raiz. A água da chuva se inflita (sic) na terra se juntando com os nutrientes, depois a água junta com os nutrientes e alimentos pelo caule". No $7^{\circ}$ ano ainda em $44,4 \%$ das citações os alunos fazem menção a uma nutrição pelas raízes ou relacionada ao solo (raiz/ terra/ adubo/ água/ chuva).

É importante assinalar que este percentual é inferior ao observado na $4^{a}$ série e que o percentual de citações da fotossíntese como a fonte de nutrientes é de mais de $50 \%$ no 70 ano. As atividades desenvolvidas no $6^{\circ}$ ano parecem ter contribuído para os alunos abandonarem a ideia de que o solo e substâncias inorgânicas nutrem as plantas. Tal concepção é desenvolvida muitas vezes de forma equivocada pela maneira imprópria de nomear água e sais como nutrientes necessários à planta. Estas substâncias são de fato necessárias, porém não deveriam ser denominadas nutrientes para a planta. 


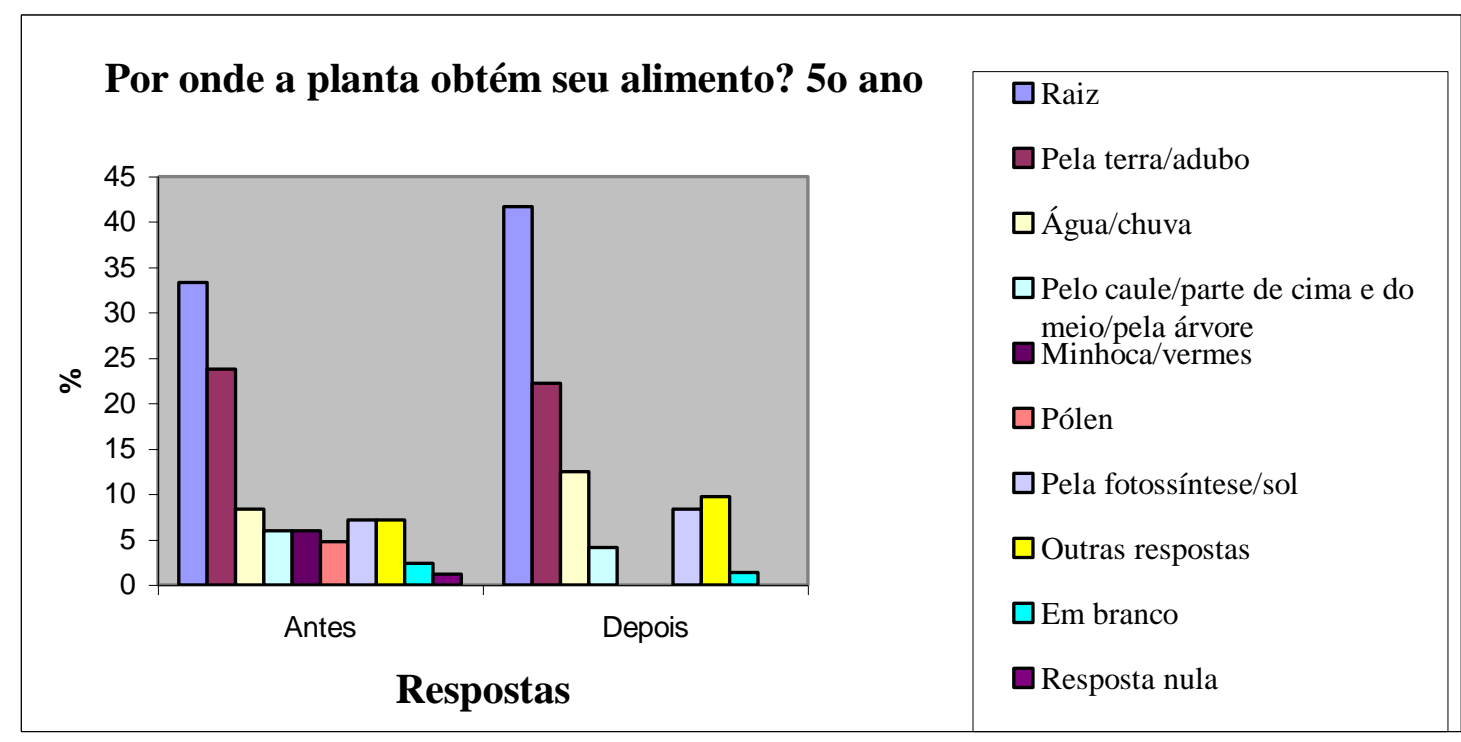

Figura 7. Respostas (\%) dos alunos do $5^{\circ}$ ano antes e depois da aula sobre reprodução das plantas à questão "Por onde a planta obtém seu alimento?" (SANTOS et al, 2005).

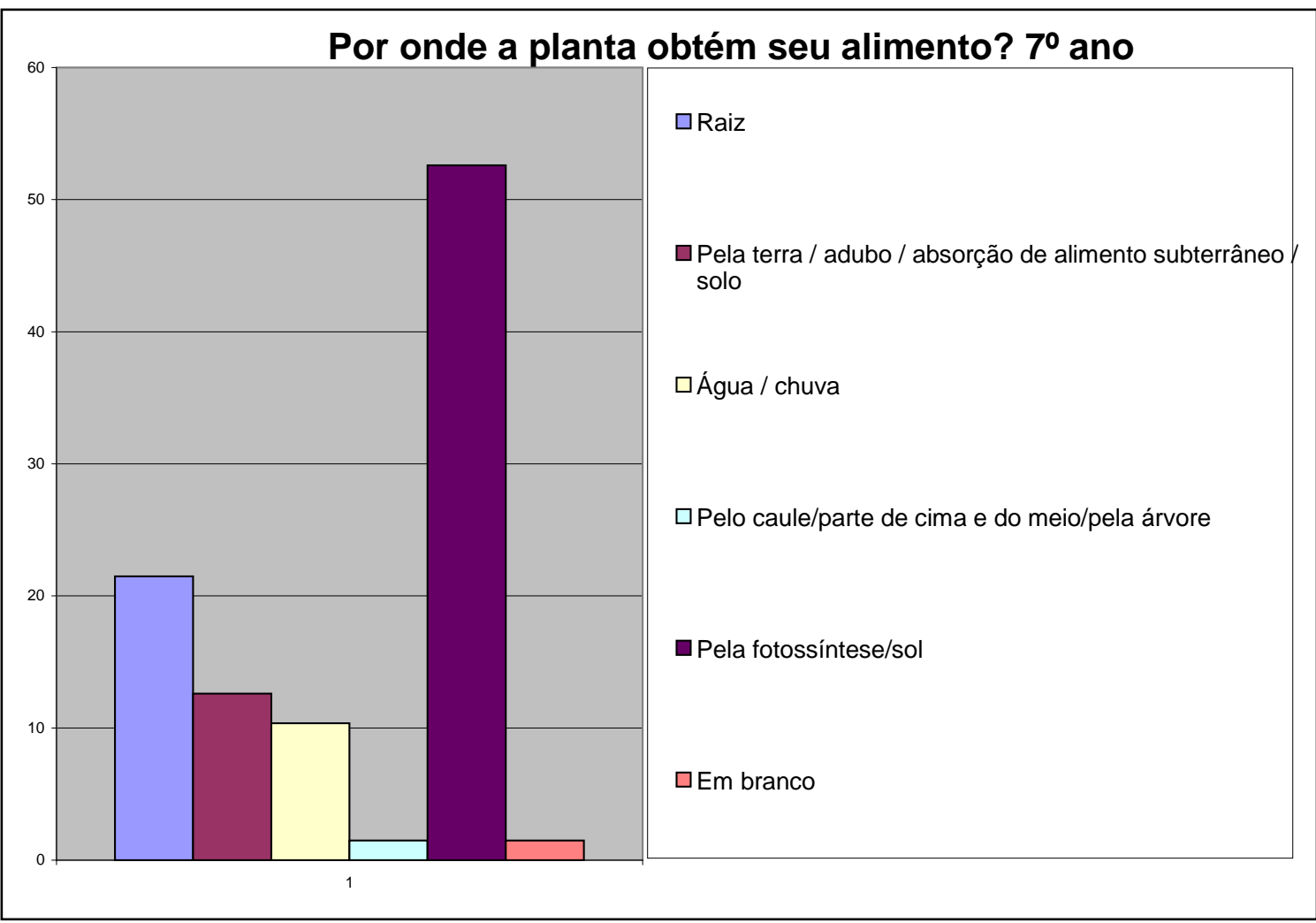

Figura 8. Respostas (\%) dos alunos do 70 ano à questão "Por onde a planta obtém seu alimento?" 
e-Mosaicos - Revista Multidisciplinar de Ensino, Pesquisa, Extensão e Cultura do Instituto de Aplicação Fernando Rodrigues da Silveira (CAp-UERJ)

ANO 1 - V. 1 - N. 1 - JUNHO 2012 - ISSN: 2316-9303

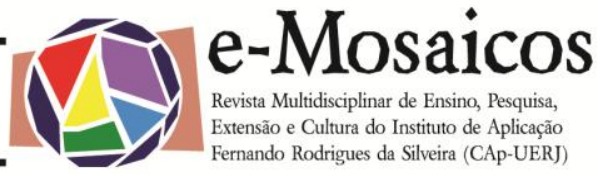

Kawasaki e Bizzo (2000) também observaram que os alunos apresentavam concepções errôneas sobre nutrição vegetal e fotossíntese. Podem neste caso refletir ideias a respeito de "nutrição", "alimento", "energia" e "respiração" que o aluno traz para dentro da escola, conforme sua experiência anterior. As concepções dos alunos, de que os alimentos das plantas são obtidos pelas interações entre solo e planta, refletem o modelo terra-raiz proposto por Aristóteles, e esta tendência é bem documentada na literatura especializada (KAWASAKI \& BIZZO, 1999).

A flor foi citada como uma estrutura reprodutiva em $23,6 \%$ das respostas dos alunos do $7^{\circ}$ ano e cerca de $20 \%$ no $5^{\circ}$ ano (Figuras 9 e 10). Entretanto, 54,5\% das respostas no $7^{\circ}$ ano associaram esta estrutura com alguma atividade humana: plantas or- namentais (enfeite) em 19,8\%, perfume com $19,4 \%$ e comida com $15,3 \%$ (Figura 10). Apesar de haver respostas sobre a ação de polinizadores ou ajudantes na reprodução de vegetais, nenhum dos grupos citou a cor e/ou o cheiro da flor como fatores de atração para os animais polinizadores (Figura 10).

Nas citações livres dos alunos da $4^{a}$ série $\left(5^{\circ}\right.$ ano) há nítida visão antropocêntrica da função da flor. Eles mencionam mais as atribuições da flor na vida do homem. Já nas citações livres dos alunos do 70 ano, apareceram respostas relacionadas às funções das plantas em geral e não especificamente das flores: sete citaram a fotossíntese e dois a produção de oxigênio e manutenção de outros seres vivos como função das flores.

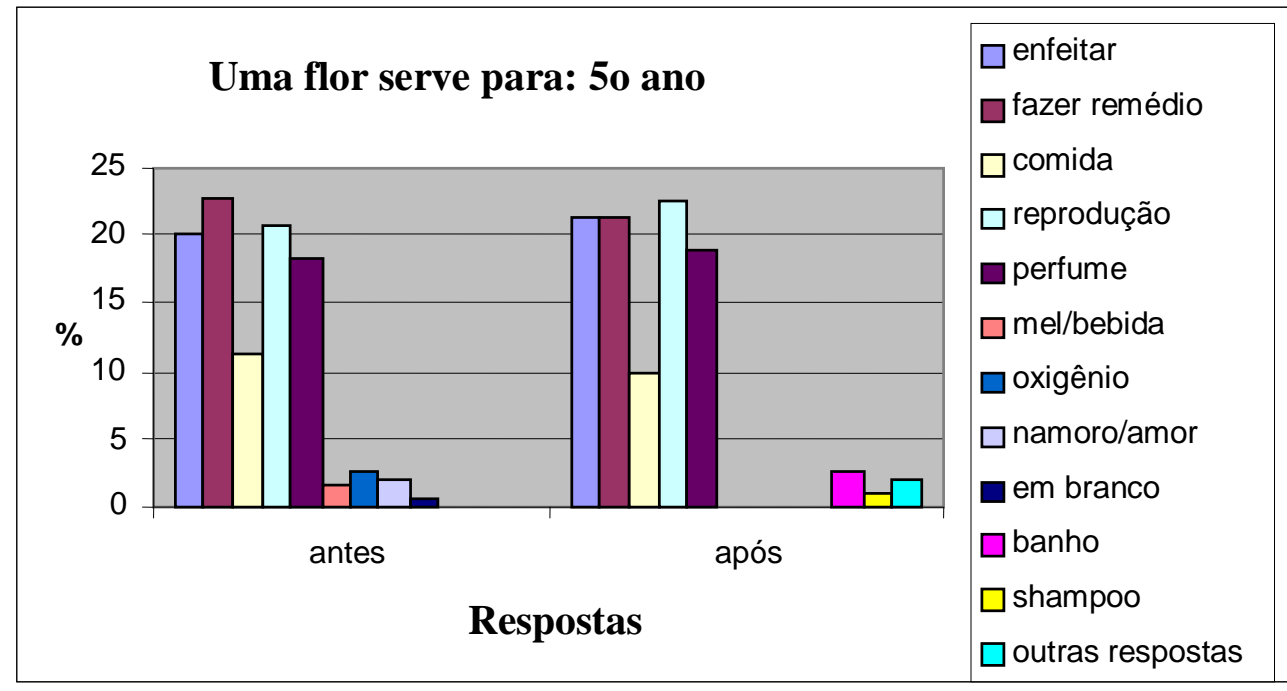

Figura 9. Respostas (\%) dos alunos do $5^{\circ}$ ano (4 $4^{\mathrm{a}}$ série) antes e depois da aula sobre reprodução das plantas à questão "Uma flor serve para..." (SANTOS et al, 2005). 


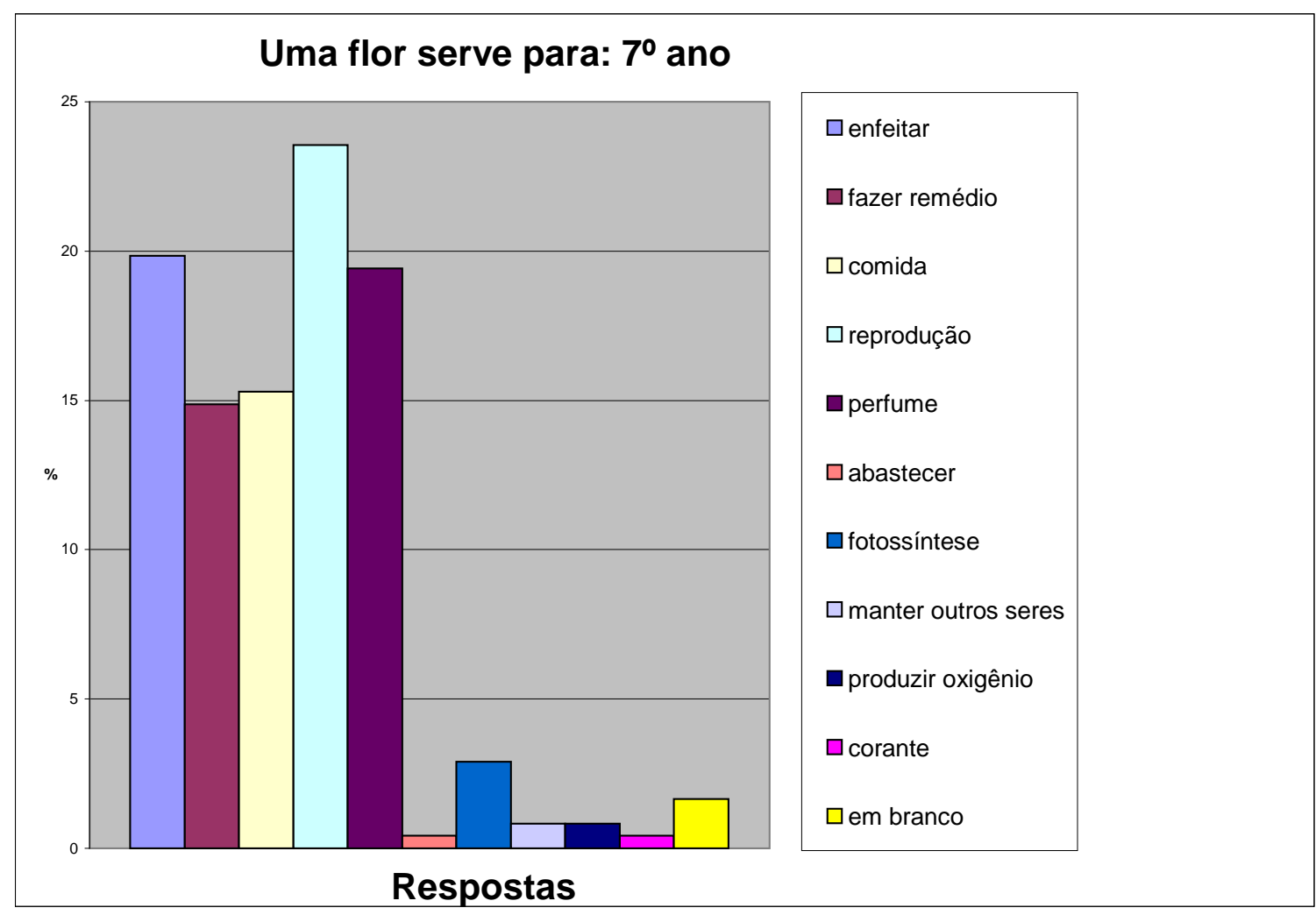

Figura 10. Respostas (\%) dos alunos do 70 ano à questão "Uma flor serve para...".

Os alunos pensam nas plantas como seres mais simples que os animais e associam as plantas às atividades humanas, como por exemplo, a função da flor na ornamentação de ambientes. Estes dois exemplos parecem demonstrar um outro modo de compreender os vegetais por estes alunos. Concepções prévias de estudantes em relação à complexidade dos seres vivos e de certas atividades humanas como a agricultura e cultivo de plantas ornamentais podem contribuir para a dificuldade na compreensão dos conceitos científicos.

A ciência apresenta de modo geral a realidade do mundo natural de forma fragmentada, o que resulta em uma apresentação de conceitos científicos muitas vezes de modo abstrato, confuso e sem sentido para o público em geral e para os discentes em particular. Assim as experiências cotidianas dos alunos são expressas sem base científica, 0 que pode levá-los a não questionar o mundo ao seu redor, acarretando em uma préformulação de conceitos tidos como unicamente corretos (ALMEIDA, 2005; MORIN, 2000).

Várias estratégias podem auxiliar o estudante na correlação de fenômenos biológicos no seu dia-a-dia. Entre elas podemos citar o ambiente da aula sendo ministrada em locais como jardins botânicos (SENICIATO \& CAVASSAN, 2004) ou no uso de materiais didáticos alternativos (SANTOS et al, 2006). Esta última estratégia vem 
e-Mosaicos - Revista Multidisciplinar de Ensino, Pesquisa, Extensão e Cultura do Instituto de Aplicação Fernando Rodrigues da Silveira (CAp-UERJ) ANO 1 - V. 1 - N. 1 - JUNHO 2012 - ISSN: 2316-9303

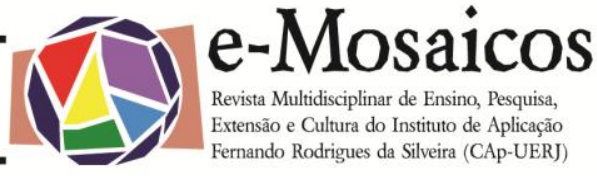

sendo executada em turmas do segundo segmento do ensino fundamental do CApUERJ.

\section{CONCLUSÕES}

Os materiais produzidos pelo Projeto Herbário Didático podem ser usados como recursos alternativos nas aulas de Ciências e Biologia de forma a contribuir para a compreensão dos fenômenos biológicos de modo mais integrado, estimulando nos alunos a observação da natureza e das relações entre os seres vivos.

O nosso estudo analisou e comparou as concepções sobre a reprodução e nutrição dos vegetais dos alunos do ensino fundamental do CAp-UERJ em dois momentos de suas vidas na escola: no $5^{\circ}$ ano do primeiro segmento e no $7^{\circ}$ ano do segundo segmento. Algumas concepções em 2007 aproximavam-se mais dos conceitos científicos e outras não mudaram significativamente nestes dois anos. Estes resultados são importantes para a compreensão das principais dificuldades dos alunos no processo de ensinoaprendizagem em ciências.

\section{REFERÊNCIAS BIBLIOGRÁFICAS}

ALMEIDA R. O. Noção de Fotossíntese: obstáculos epistemológicos na construção do conceito científico atual e implicações para a educação em ciência Candombá - Revista Virtual, v. 1, n. 1, p. $16-32$, jan - jun, 2005.

BANET, E.; AYUSO, E. Introducción a la genética en la enseñanza secundaria y bachillerato: I contenidos de enseñanza y conocimientos de los alumnos. Enseñanza de las Ciencias, 13 (2), p. 137-153, 1995.

FIDALGO, O.; BONONI, V. L. R. Técnicas de coleta, preservação e herborização de material botânico. São Paulo: Instituto de Botânica, 1984. 61 p.

HERSHEY, D. More Misconceptions to Avoid When Teaching about Plants. American Institute of Biological Sciences, 9/2005. Disponível em: http://www.actionbioscience.org/education/ hershey3.html. Acesso em: 2 Nov 2006.

HERSHEY, D. Avoid Misconceptions When Teaching about Plants. American Institute of Biological Sciences, 8/2004. Disponível em: http://www.actionbioscience.org/education/ hershey.html. Acesso em: 2 Nov 2006.

IBGE. Manual Técnico da Vegetação Brasileira. Rio de Janeiro: Fundação IBGE, Depto de Recursos Naturais e Estudos Ambientais. 1992. $92 \mathrm{p}$.

KAWASAKI, C. S.; BIZZO, N. Fotossíntese: um Tema para o Ensino de Ciências? Revista Química Nova na Escola. n. 12, p. 24-29, novembro 2000.

KAWASAKI, C. S.; BIZZO, N. Ideias de Nutrição Vegetal: o velho dilema entre o papel nutricional das raízes e da fotossíntese. Projeto: Revista de Educação, São Paulo, v.1, n.1, p. 2-11, julho, 1999.

MORI, S. A.; SILVA, L. A. M.; LISBOA, G. ; CORADIN, L. Manual de Manejo do Herbário Fanerogâmico. Ilhéus, Bahia: Ed. Centro de Pesquisas do Cacau, CEPLAC/CEPEC, 1985. 97p.

MORIN, E. A cabeça bem feita: repensar a reforma, reformar o pensamento. 2. ed. Rio de Janeiro: Bertrand Brasil, 2000. 128p.

MORIN, E. Os sete saberes necessários à educação do futuro. São Paulo: Ed. Cortez/UNESCO. 2001. 118 p.

SANTOS, M. C. F. et al. O que pensam os alunos da 4a série do Ensino Fundamental 
e-Mosaicos - Revista Multidisciplinar de Ensino, Pesquisa, Extensão e Cultura do Instituto de Aplicação Fernando Rodrigues da Silveira (CAp-UERJ)

ANO 1 - V. 1 - N. 1 - JUNHO 2012 - ISSN: 2316-9303

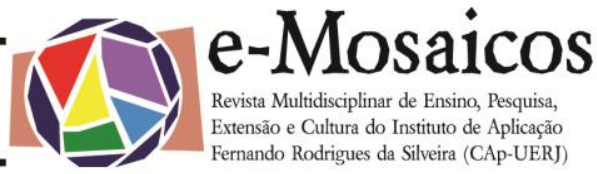

do CAp/UERJ sobre a reprodução das plantas?. IV Simpósio Educação e Sociedade Contemporânea - Desafios e Propostas, 2005. In: Anais... Rio de Janeiro: Universidade do Estado do Rio de Janeiro, 2005.

SANTOS, M. C. F. et al. Concepções prévias dos alunos da $6^{\text {a }}$ série do ensino fundamental do CAp/UERJ sobre as plantas e sua diversidade. V Simpósio Educação e Sociedade Contemporânea - Desafios e Propostas, 2006. In: Anais... Rio de Janeiro: Universidade do Estado do Rio de Janeiro, 2006.

SENICIATO, T. \& CAVASSAN, O. Aulas de Campo em Ambientes Naturais e Aprendizagem em Ciências - Um Estudo com alunos do Ensino Fundamental. Ciência \& Educação, v. 10, n. 1, p. 133-147, 2004.

SINGH, G. Plant Systematics. USA: Science Publisher

${ }^{1}$ mcfs@uerj.br - Mestre em Ciências Biológicas pela Universidade Federal do Rio de Janeiro. É doutoranda em Educação na Universidade Federal Fluminense. Atualmente é docente da Universidade do Estado do Rio de Janeiro, atuando no Instituto de Aplicação Fernando Rodrigues da Silveira - CAp-UERJ e na Faculdade de Formação de Professores, onde participa do Núcleo de Pesquisa e Ensino de Ciências.

${ }^{2}$ Iccaguiar@terra.com.br - Licenciada em Ciências Biológicas pela Universidade Federal do Rio de Janeiro (1988) e Mestre em Química Biológica pela Universidade Federal do Rio de Janeiro (1997). Atualmente é Professora Docente I da Secretaria de Estado de Educação e Professora Assistente da Universidade do Estado do Rio de Janeiro / Instituto de Aplicação Fernando Rodrigues da Silveira - CAp-UERJ. Trabalha na área de Ensino de Ciências e Biologia, com ênfase em Materiais e Metodologias de Ensino e Aprendizagem. Atua principalmente nos seguintes temas: Produção de currículos, instrumentos de avaliação e materiais didáticos; Instrumentalização de
Ensino e Formação Continuada para professores.

3 annadecio@uol.com.br - Graduada em Ciências Biológicas pela Faculdade de Humanidades Pedro II (1985) e Mestre em Morfologia (Histologia e Embriologia) pela Universidade do Estado do Rio de Janeiro (1990). Atualmente é Professora Assistente da Universidade do Estado do Rio de Janeiro / Instituto de Aplicação Fernando Rodrigues da Silveira - CAp-UERJ, lecionando no Ensino Fundamental, Médio e Superior (Curso de Licenciatura em Ciências Biológicas) e Professora Auxiliar da Universidade Gama Filho, lecionando para os Cursos de Medicina, Odontologia, Ciências Biológicas, Enfermagem, Farmácia e Nutrição. Tem experiência na área de Biologia Celular e Molecular, Histologia e Embriologia Humana e Embriologia Comparada.

${ }^{4}$ gamon@globo.com - Mestre em Ciências (Microbiologia) pela Universidade Federal do Rio de Janeiro (1996). Tem experiência na área de Microbiologia, na área de Bacteriologia Geral e Médica, com ênfase em Genética de microrganismos. Atualmente é Professor Assistente da Universidade do Estado do Rio de Janeiro / Instituto de Aplicação Fernando Rodrigues da Silveira - CAp-UERJ. Vem atuando ou já atuou principalmente nos seguintes temas: 1) Projetos de extensão: A) Divulgação Científica: biodiversidade em bactérias na capacitação, montagem e organização de coleções biológicas e B) Importância da biologia molecular e da microbiologia (bactérias) em sala de aula (INTERCAp); 2) Formação de professores em disciplinas de Licenciatura: prática de ensino e tópicos em investigação científica; 3) Orientação/Supervisão de estudantes em Iniciação à docência em biologia/ciências pelo CAp-UERJ. 4) Co-orientação de estudantes em iniciação científica (Herbário Didático do (Ap-UERJ) e 5) Colaboração em atividades de avaliação no uso de bactérias na área de biorremediação. Também é professor da FAETEC na área de patologia clínica ministrando disciplinas de Imunologia e biossegurança. 